four hours for bottle feedings." The experimental group of 14 mothers were in addition "given their nude babies, with a heat panel overhead, for one hour within the first three hours after birth, and also five extra hours of contact each afternoon of the three days after delivery."

To determine whether this additional time with the infant altered later behaviour they brought the mothers back 28 to 32 days after delivery for a standardized interview, for observation when the infant was being examined, and for a filmed study of the mother feeding her baby. Mothers were asked, "When the baby cries and has been fed, and the diapers are dry, what do you do?" (Score of 0 for "letting the baby cry it out," 3 for "picking up the baby every time.") Another question was, "Have you been out since the baby was born, and who sat?" (Score 0 for "yes" and "if the mother felt good and did not think about her infant while she was out." A score of 3 "if she did not go out or leave the baby with anyone, or if she did go out but thought constantly about the baby.") During the examination of the baby a mother scored 3 if "she was standing by the pediatrician and watching continuously"; a score of 0 if "she remained seated and looked elsewhere." The experimental group, which had more contact with their babies, secured a higher score than the control group.

It is always difficult to know how far the results of animal studies are applicable to human beings. Many studies have shown that separation of the newborn animal from his mother immediately after birth has a bad effect both on the young and on the mother's attitude to her young. ${ }^{4-10}$ For instance, if a newborn kid is separated from his mother for only 15 to 45 minutes after birth and then returned to his mother, she rejects the kid and butts it, refusing to allow it to suckle. ${ }^{11}$ Goats, sheep, and other animals need to lick their young at birth, particularly in the genital area, and failure to do so leads to rejection. Puppies separated from their mothers at birth tend to be less affectionate and more difficult to train. When newborn rats are separated from their mothers at birth and then returned, the mothers nurse them less and do not bother to "retrieve" them-that is, to bring them back to the nest if they wander away or are placed at a distance away. It seems that continuous association with actively suckling young is necessary for the development of normal maternal behaviour, and if mothers are deprived of it their quality of mothering suffers.

Mothers in a maternity unit sometimes say that they feel the urge to have skin contact with the baby immediately he has been born. Some want to put him to the breast immediately. Some feel that it is important that they should be fully conscious at the time of delivery and not under an anaesthetic. Human studies of the effect of such instincts or of interference with them are fraught with difficulties because of all the variables involved, but in the present state of our knowledge it is wise to respect the instincts. It would certainly seem wrong to prevent a mother from handling her baby if she wants to do so. After all, the baby is hers, she has nurtured him for some nine months, and it seems unnatural to separate mother and child unless the child is ill or is a small premature baby needing special care. Even then $i_{i}$ is the practice of many paediatricians in Britain to encourage mothers to handle their premature babies and to feed them and clean them up, because separation of mother and baby might harm the mother-child relationship. A particular problem arises when babies are born with a handicap, such as spina bifida or difficult metabolic problems. It would be sensible to try to reduce to a minimum the duration of these babies' stay in hospital and to try to encourage contact between mother and child. When a child is eventually discharged home after a long stay in hospital from birth because of a major handicap or some obscure error of metabolism, it is not uncommon for the mother to reject her child.

We need to pay more thought to anything which severs the natural bond between the newborn and his motherbottle feeding instead of breast feeding, separation of the baby by putting him in a nursery, discouragement of the mother from picking the baby up when he cries or feeding him when he is hungry-or anything which prevents her enjoying him or his enjoying her.

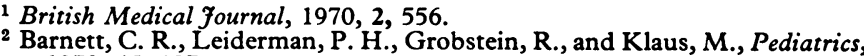
1970, 45, 197.

3 Klaus, M. H., et al., New England fournal of Medicine, 1972, 286, 460.

4 Vaughan, V. C., Fournal of the American Medical Association, 1966, 198, 45.

${ }^{5}$ Rheingold, H. L., in Maternal Behavior in Mammals. New York, John Wiley, 1963.

- Denenberg, V. H., Stimulation in Early Infancy, ed. A. Ambrose. London, Academic Press, 1969

'Hersher, L., Richmond, J. B., and Moore, A. U., in Maternal Behavior in Mammals. New York, John Wiley, 1963.

${ }^{8}$ Ambrose, A., in Foundations of Child Psychiatry. Oxford, Pergamon, 1968. Harlow, H. F., and Harlow, M. K., in Determinants of Infant Behavior, ed. Foss, B. M., vol. IV. London, Methuen, 1969.

${ }_{10}$ Hersher, L., Moore, A. U., and Richmond, J. B., Science, 1958, 128, 1342.

1 Collias, N. E., Ecology, 1956, 37, 228.
}

\section{Cardiac Biopsy}

Though there has been considerable progress in the diagnosis and investigation of cardiac disease, a group of disorders remain, collectively known as the cardiomyopathies, in which the aetiology and pathological classification await clarification. Knowledge of renal, hepatic, gastrointestinal, and to a lesser extent pulmonary disease has advanced rapidly since the introduction of simple biopsy techniques permitting the correlation of the pathological features with the clinical and metabolic manifestations. Cardiac biopsy has not been so enthusiastically supported, and consequently knowledge of the cardiomyopathies has been based primarily on the clinical and haemodynamic features. Without an understanding of pathogenesis, it is not surprising that treatment has been empirical and generally unsatisfactory. The diagnosis of the cardiomyopathies is often only presumptive during life. The pathological features have until recently been determined solely at necropsy, but this discloses only the final stage in a protracted pathological process, which will have been modified by metabolic alterations during the terminal illness and by post-mortem autolysis.

Several techniques of cardiac biopsy have been described. A biopsy may be taken at the time of open heart surgery, or a small thoracotomy may be electively performed to obtain cardiac tissue. ${ }^{12} \mathrm{~A}$ thoracotomy, however limited in extent, is a major procedure, which though having advantages is unlikely to find a place in the routine assessment of patients with myocardial disease. A variety of percutaneous techniques have been used for cardiac biopsy,,$^{3-6}$ the usual approach being similar to that for left ventricular puncture. ${ }^{7}$ Though relatively free from complications, a percutaneous approach may be frightening for the patient, and the dangers of pneumothorax, cardiac tamponade, and unexplained hypotension are present. ${ }^{8}$ Furthermore, the amount of tissue obtained is often inadequate. During the last decade S. Konno and his colleagues ${ }^{910}$ in Japan have developed an 
intracardiac technique for obtaining specimens of endocardial and myocardial tissue. The "endomyocardial bioptome" is adapted to an ordinary intracardiac catheter. A screw at the proximal end allows the operator to open and close a biting claw at the distal exploring end. The bioptome is guided under fluoroscopic control to the chosen cardiac chamber via an artery or vein, contact with the ventricular wall being signalled by intracardiac electrocardiographic changes. A sizable biopsy of both endocardium and myocardium may be obtained by this method, and tissue may be taken from more than one site. In a large number of patients this technique has been free of complication and the rate of success has been high. ${ }^{10} 11$ The technique is readily acquired and may be employed as an adjunct to routine cardiac catheterization. ${ }^{11} \mathrm{~A}$ method of intracardiac biopsy of the interventricular septum has also been described. 12

The Konno technique is a satisfactory and safe method of cardiac biopsy, and it is now possible to study hitherto obscure primary myocardial diseases. Secondly, myocardial diseases such as sarcoidosis, amyloidosis, haemochromatosis, glycogen storage disease, and the collagen disorders can usually be diagnosed without recourse to biopsy, but in doubtful cases biopsy will usually be diagnostic. ${ }^{13}$ Light microscopy has been disappointing in the elucidation of primary myocardial disease, but with electron miscroscopy and advances in histochemical, virological, and immunological techniques it is to be hoped that a better understanding of the pathogenesis of these disorders will be possible. Recent studies of myocardial biopsies in the cardiomyopathies are disclosing considerable histopathological detail,11 13-15 but the morphological changes are often lacking in specificity, and at present cardiac biopsy must be regarded primarily as a research technique, to be used with scrubulous ethical safeguards, in the study of primary myocardial disease.

\footnotetext{
1 Weinberg, M., Raffensberger, J., Driscoll, J. F., Sutton, G. C., and Tobin,

J. R., Circulation, 1963, 28, 823.
2 Sutton, G. C., Driscoll, J. F., Gunnar, R. M., and Tobin, J. R., Progress in Cardiovascular Diseases, 1964, 7, 83.

3 in Cardiovascular Diseases, 1964, 7, 83.

3 Sutton, D. C., and Sutton, G. C., American Heart Fournal, 1960, 60, 364. Brasileiros de Cardiologia, 1962, 15, 307.

5 Soubihe, N. V., Archivos del Instituto de Cardiologiá de Mexico, 1963,

33, 132. Heinz, J., Choudhry, A.-S., and Cabrera, P., American fournal of Cardiology, 1964, 14, 675 .

7 Brock, R., Milstein, B. B., and Ross, D. N., Thorax, 1956, 11, 163.

Brockenbrough, E. C., Morrow, A. G., Talbert, J., and Braunwald, E. British Heart Fournal, 1961, 23, 643.

${ }^{9}$ Konno, S., and Sakakibara, S., Diseases of the Chest, 1963, 44, 345.

10 Konno, S., Sekiguchi, M., and Sakakibara, S., Radiologic Clinics of North America, 1971, 9, 491 .

11 Somers, K., Hutt, M. S. R., Patel, A. K., and D'Arbela, P. G., British Heart fournal, 1971, 33, 822.

12 Bulloch, R. T., Murphy, M. L., and Pearce, M. B., American fournal of Cardiology, 1965, 16, 227.

13 Sekiguchi, M., and Konno, S., fapanese Heart fournal, 1969, 10, 30.

14 Takatsu,' T., Kawai, C., Tsutsumi, J., and Inoue, K., American Heart fournal, 1968, 76, 93.

15 Bulloch, R. T., Pearce, M. B., Murphy, M. L., Jenkins, B. J., and Davis, J. L., American fournal of Cardiology, 1972, 29, 15.
}

\section{Treatment of Gonorrhoea}

An ideal agent for the treatment of gonorrhoea is one which is non-toxic, effective in a single dose, preferably given parenterally, and which does not affect Treponema pallidum. Penicillin meets these needs except for the last, and it has long been the treatment of choice, though its effectiveness is now blunted by the emergence of strains of gonococci of diminished sensitivity. Today about a third of the strains in circulation in London need concentrations of penicillin of $0.06 \mu \mathrm{g} / \mathrm{ml}$ serum or more for inhibition; the least sensitive strains need $1 \mu \mathrm{g} / \mathrm{ml}$. Such strains are not truly resistant and penicillin can still be used effectively against them if it is given in sufficient dosage.

For uncomplicated infections a single dose of 2.4 mega units of procaine penicillin intramuscularly, preceded by $2 \mathrm{~g}$ probenecid orally to delay excretion, gives good results. G. A. Olsen and G. Lomholt ${ }^{1}$ and R. C. F. Gray and others $^{2}$ have had only 0.5 to $1 \%$ of failures with 5 megaunits of benzyl penicillin preceded by probenecid. These results would be difficult to better, but the amount given is about the most which can be given in a single injection. There is general agreement that slow release penicillins and phenoxymethyl penicillin should not be used to treat gonorrhoea. Ampicillin has given good results. G. Eriksson ${ }^{3}$ reported only 2 to $3 \%$ of failures after two doses of $1 \mathrm{~g}$ given at an interval of five hours or a single dose of $2 \mathrm{~g}$ preceded by probenecid; $2 \mathrm{~g}$ ampicillin given as a single dose was less effective.

A history of previous intolerance to penicillin, the suspicion of a concomitant syphilitic infection, or failure after an adequate dose of penicillin call for other means of treatment. A. E. Wilkinson, J. W. Race, and F. R. Curtis ${ }^{4}$ found only $3 \%$ of failures after a single dose of $2 \mathrm{~g}$ kanamycin, which did not produce any toxic reactions. This antibiotic is not treponemicidal and so can be given when there is a possibility of a double infection with syphilis and gonorrhoea. This is also true of trimethoprim-sulphonamide mixtures, which have proved effective against the gonococcus. B. R. T. Carroll and C. S. Nichols have reported a cure rate of 93 to $95 \%$ after a dose of four tablets, each containing $80 \mathrm{mg}$ trimethoprim and $400 \mathrm{mg}$ sulphamethoxazole, given daily for five days. Strains of gonococci which are insensitive to penicillin also show decreased sensitivity to other antibiotics such as streptomycin, spiramycin, and tetracycline. Penicillin-insensitive strains are almost always highly resistant to streptomycin, and this should no longer be used to treat gonorrhoea.

There appears to be little difference between the effectiveness in vitro of the different tetracyclines against gonococci. Tetracycline itself at a dosage of $500 \mathrm{mg}$ four times daily for a minimum of two days still gives good results in Britain but should not be used if concomitant syphilis is suspected. However, J. B. Lucas ${ }^{6}$ has reported that in the United States in 1965 only $12 \%$ of strains required tetracycline $1 \mu \mathrm{g} / \mathrm{ml}$ for inhibition. Since then the figure has steadily risen and by 1970 had reached $67 \%$. A similar but less obvious trend for both tetracycline and spiramycin has been reported from France by G. Niel and his colleagues. ${ }^{7}$ These findings suggest that the tetracyclines may become less effective in Britain in the future. A single dose of 900 $\mathrm{mg}$ rifampicin by mouth has been used by $\mathrm{R}$. $\mathrm{R}$. Willcox and others. ${ }^{8}$ This gives high serum levels, and the drug does not affect $T$. pallidum. However, there were ten treatment failures among 103 males so treated. A. G. Malmborg and others ${ }^{9}$ treated 100 males and 100 females with gonorrhoea by the same dose. They had 25 treatment failures and noted that in 11 of these the gonococci, which were originally sensitive, had become resistant to rifampicin. Because of the high failure rate and the rapid development of resistance, rifampicin should not be used to treat gonorrhoea.

The sensitivity of gonococci to different antibiotics varies 